\title{
Evaluation of the Association between Natural Mold Resistance and Chemical Components of Nine Wood Species
}

\author{
Jing Feng, ${ }^{\mathrm{a}}$ Chengbin Li, ${ }^{\mathrm{a}}$ Juan Chen, ${ }^{\mathrm{b}}$ Mingjie Chen, ${ }^{\mathrm{a}}$ Xiulin Shu, ${ }^{\mathrm{a}}$ and Qingshan Shi ${ }^{\mathrm{a}, *}$
}

The association between natural mold resistance and the wood's chemical components was studied for nine wood species. The mold resistance of the different wood species was tested by artificially accelerated tests and scanning electron microscopy (SEM). The chemical components were analyzed by gas chromatography-mass spectrometry (GC-MS). The results indicated that the sequence of mold resistance of different wood flours was as follows, from greatest to least resistance: spruce, Mongolian pine and camphor, toon and teak, eucalyptus (E. urophylla and E. grandis $x$ E. urophylla), sweetgum, and castor straw fiber. GC-MS analysis indicated that the total contents of the antifungal compounds present in all wood flour extractives were consistent with the sequence of mold resistance of wood flour. This suggested that the natural durability of wood flour against molds was affected by its chemical components.

Keywords: Mold; Mold resistance; Wood flour; Chemical components

Contact information: a: Guangdong Institute of Microbiology, State Key Laboratory of Applied Microbiology Southern China, Guangdong Provincial Key Laboratory of Microbial Culture Collection and Application, Guangdong Open Laboratory of Applied Microbiology, Guangzhou 510070, China;

b: Guangdong Demay Biotechnology Co., LTD, Guangzhou 510070, China;

*Corresponding author: jigan@gdim.cn

\section{INTRODUCTION}

Wood and wood products mainly consist of cellulose, hemicellulose, lignin, and extractives. They have been widely applied in buildings, furniture, and paper pulp production due to their advantages, such as high strength-weight ratio, impact resistance, and high processability ( $\mathrm{Li}$ et al. 2015). With the continuous decline of forest resources and their increasing prices, wood fibers (or biomass fibers), which come from both forest and agricultural residues, are now increasingly being used as fillers in wood composites, such as wood-plastic composites, wood-metal composites, wood-inorganic composites, and wood-glass fiber composites.

Due to their susceptibility to weathering and hygroexpansion, wood and wood products are prone to attack from biological pathogens, such as wood-decay fungi and molds (Li et al. 2015; Salem et al. 2017). Wood-decay fungi change the chemical structure of lignin, cellulose, and hemicellulose, resulting in a substantial loss of weight and strength (Durmaza et al. 2016). Molds growing on wood surfaces do not degrade cellulose, lignin, and hemicellulose in wood. Hence, they do not always deteriorate its mechanical and physical properties. However, the large quantities of cellulolytic enzymes (cellulases and hemicellulases), extracellular metabolites, and pigments produced by molds cause discoloration or staining on the wood surface (Sirmah et al. 2009; Sohail et al. 2011). Under favorable conditions of high moisture content, molds cause disfigurement of wood in a 
very short time, and with their strong propagation, some lead to soft rot of lignocellulosic materials (Fojutowski et al. 2014). Furthermore, the growth and colonization of molds on wood surfaces provide a medium for other deterioration agents such as insects and decay fungi, which disseminate into cells through cell walls, pores, and pits (Sterflinger and Piñar 2013; Salem 2016). In general, the deterioration of physical and mechanical properties of wood and wood products results from a combination of biological agents.

The resistance to fungal attack varies among wood species. Wood species are mainly composed of carbon, oxygen, hydrogen, nitrogen, and several metal ions (Salem 2016). The elemental composition changes with wood species, which significantly influences its fungal susceptibility. Sugars and starches present in wood provide a suitable environment for growth and reproduction of fungi, which alter the properties of wood and wood products (Mansour and Salem 2015; Salem 2016). There are different types and contents of chemical components in various wood species (Xu et al. 2015). Some wood species contain highly toxic chemical substances, such as tannins, fatty acids, aldehydes, and ketones, which result in a passive or negative effect on the susceptibility and resistance of wood against fungi (Jeloková and Šindler 2001; Liu et al. 2008).

There is little information regarding the effects of chemical components of different wood species on the susceptibility of mold growth on wood flour. Thus, the aim of this work was to evaluate the associations between the natural mold resistance and the chemical components of wood flour species. Wood flours from spruce, Mongolian pine, castor straw fiber, camphor, toon, teak, sweetgum, and two eucalyptus species (Eucalyptus urophylla and $E$. grandis $\times E$. urophylla) were examined. The natural mold resistances of various wood species were examined and estimated using artificially accelerated tests. Meanwhile, surface and fracture morphology of wood specimens were observed by scanning electron microscopy (SEM). The components of wood flour species were extracted via Soxhlet apparatus and analyzed by gas chromatography-mass spectrometry (GC-MS).

\section{EXPERIMENTAL}

\section{Materials}

Wood flour from nine different species, including spruce (Picea asperata), Mongolian pine (Pinus sylvestris var. mongolica), castor straw fibers (Ricinus communis), camphor (Cinnamomum camphora), toon (Toona ciliate), teak (Tectona grandis), sweetgum (Liquidambar formosana), and two eucalyptus species (Eucalyptus urophylla and $E$. grandis $\times E$. urophylla), were obtained from a commercial factory. Before being used, the wood flours were ground and sieved with sizes of 20 mesh to 100 mesh, and then dried to a constant weight at $105^{\circ} \mathrm{C}$.

Five mold specimens, including Aspergillus niger (GIM 3.5487), Trichoderma viride (GIM 3.139), Penicillium funiculosum (GIM 3.103), Aureobasidium pullulans (GIM 3.44), and Chaetomium globosum (CGMCC 3.3601), were supplied by the Microbial Culture Collection Center of the Guangdong Institute of Microbiology, Guangzhou, China.

\section{Methods}

Accelerated mold resistance test

The mold resistance of wood flour species was tested using an artificially accelerated method. First, A. niger, T. viride, P. funiculosum, A. pullulans, and C. globosum were grown separately and maintained in Petri plates on potato dextrose agar (PDA) 
medium (containing $200 \mathrm{~g} / \mathrm{L}$ of potato extract, $20 \mathrm{~g} / \mathrm{L}$ of glucose, and $20 \mathrm{~g} / \mathrm{L}$ of agar) at 28 $\pm 2{ }^{\circ} \mathrm{C}$ and $85 \%$ relative humidity for $10 \mathrm{~d}$ to $15 \mathrm{~d}$, until the whole surface of the plate was sufficiently covered with fungal hyphae and mycelia. A spore suspension of each of the five test molds was prepared by washing the surface of each fungal culture with 10 to 15 $\mathrm{mL}$ of sterile water. The suspension was transferred to a sterile Erlenmeyer flask that contained sterile water and glass beads. The flask was vibrated vigorously to separate the spores. A precipitate was obtained after filtration and centrifugation of the spore suspension. The precipitate was then re-suspended in $100 \mathrm{~mL}$ of sterile water, which yielded approximately $1 \times 10^{7}$ spores $/ \mathrm{mL}$. This procedure was repeated for each mold. Equal volumes of the resultant spore suspensions were blended to obtain the final spore suspension mixture. This suspension was then transferred to a $50 \mathrm{~mL}$ spray bottle and used as the source of fungal inoculum for testing.

Prior to the mold resistance testing, each of the dried wood flours was mixed with sterile water at a water to wood flour ratio of $20 \%(\mathrm{v} / \mathrm{m}, \mathrm{mL} / \mathrm{g})$. All wood flour specimens were sprayed with equal amounts of the mixed spore suspension and incubated at $28{ }^{\circ} \mathrm{C} \pm$ $2{ }^{\circ} \mathrm{C}$ with $85 \%$ relative humidity for $28 \mathrm{~d}$. Following incubation, the mold ratings of wood flour were rated visually according to ASTM G21 (2013) with ratings of 0 to 4, where 0 indicated no mold growth, and 4 indicated heavy mold growth (60\% to complete coverage).

\section{Scanning electron microscopy}

Microbial growth on the surface of each wood flour sample before and after mold resistance test was observed using a scanning electron microscope (Hitachi S-3000N, Guangzhou, China) at an accelerating voltage of $15 \mathrm{kV}$. Each wood flour sample was dried and sputter-coated with a thin layer of gold prior to observation.

\section{Extraction of the chemical components of wood flour}

Wood flour samples were air-dried and extracted by the Soxhlet method with benzene/ethanol (absolute) (1:1, v/v) solvent. Each sample weighing $3 \mathrm{~g}$ was placed in a Soxhlet extractor for $8 \mathrm{~h}$, at a reflux rate of not less than 6 times an hour. The obtained solutions were evaporated using a rotary evaporator and then re-dissolved in $5 \mathrm{~mL}$ of methanol to obtain the extractives.

\section{Gas chromatography-mass spectrometry analysis}

The chemical components of extractives were analyzed using a gas chromatographmass spectrometer device (7890A-5975C, Agilent Technologies, Guangzhou, China) equipped with a DB-5MS silica capillary column $(30 \mathrm{~mm} \times 0.25 \mathrm{~mm} \times 0.25 \mu \mathrm{m}$, Agilent $)$. The oven temperature was initially maintained at $80{ }^{\circ} \mathrm{C}$ for $4 \mathrm{~min}$, gradually increased to $200{ }^{\circ} \mathrm{C}$ at a rate of $10{ }^{\circ} \mathrm{C} / \mathrm{min}$, and raised to $300{ }^{\circ} \mathrm{C}$ for $10 \mathrm{~min}$. The temperature of the injector was set to $290{ }^{\circ} \mathrm{C}$, and the detector was set to $300^{\circ} \mathrm{C}$. Highly pure helium was used as the carrier gas at a constant flow rate of $1.0 \mathrm{~mL} / \mathrm{min}$. The temperatures of the transfer line, quadrupole, and ion source were $250{ }^{\circ} \mathrm{C}, 150{ }^{\circ} \mathrm{C}$, and $230{ }^{\circ} \mathrm{C}$, respectively. Electron ionization (EI) was used as the ion source with an electronic energy of $70 \mathrm{eV}$ and the mass scanning range was set from 30 amu to 500 amu in full scan. The volume of the injected sample was $1 \mu \mathrm{L}$ with a split ratio of 30:1. 
The chemical components were identified by comparing their mass spectra with those published in the National Institute of Standards and Technology database (https://www.nist.gov/). The peak areas of all the components were calculated by using Xcalibur 2.0 software (Thermo Fisher Scientific, Waltham, MA, USA), and the relative contents of chemical compounds were calculated from the ratios of the peak areas.

\section{RESULTS AND DISCUSSION}

\section{Accelerated Mold Resistance of Wood Flour}

Table 1 and Fig. 1 illustrate the growth and colonization of mold and the mold ratings of nine wood flour species after an incubation period of $28 \mathrm{~d}$. There were obvious differences in the mold ratings for different wood flour species. The best mold resistance among the nine wood flour species was exhibited by the spruce wood flour. No mold growth and colonization was observed on the surface of the spruce wood flour (Fig.1A), which corresponded to the mold rating of 0 after $28 \mathrm{~d}$ of exposure. Excellent mold resistance was found in the wood flours of Mongolian pine, camphor, toon, and teak. These wood samples showed excellent durability against molds, which corresponded to very little mold growth and colonization on the surface, with mold rating at $28 \mathrm{~d}$ of level 1, as shown in Figs.1B, D, E, and F.

Among these four wood flours, Mongolian pine and camphor exhibited comparatively higher mold resistance because no mold colonies were found at $14 \mathrm{~d}$, while the rest were slightly colonized. Wood flours of two eucalyptus species (E. urophylla and $E$. grandis $\times E$. urophylla) and sweetgum showed relatively lower mold resistance. They were colonized faster $(7 \mathrm{~d})$ accompanied with medium coverage of mold, and the final mold ratings (at $28 \mathrm{~d}$ ) for these three wood flours were 2 (Figs.1G, H, and I). Castor straw fiber, as shown in Fig. 1C, exhibited the lowest resistance to mold. A heavy mold growth and colonization appeared after $7 \mathrm{~d}$ exposure (Level 3), and the final rating at $28 \mathrm{~d}$ was Level 4, which was equivalent to $100 \%$ mold coverage on the surface of castor straw fiber. Thus, the sequence of durability of different wood flours against molds was as follows: spruce $>$ Mongolian pine and camphor > toon and teak > eucalyptus (E. urophylla and $E$. grandis $\times E$. urophylla) $>$ sweetgum $>$ castor straw fiber.

Table 1. Visual Mold Ratings of Wood Flour Species after Exposure to Molds

\begin{tabular}{|c|c|c|c|c|}
\hline \multirow{2}{*}{ Wood Flour Species } & \multicolumn{4}{|c|}{ Mold Ratings } \\
\cline { 2 - 5 } & $0 \mathrm{~d}$ & $7 \mathrm{~d}$ & $14 \mathrm{~d}$ & $28 \mathrm{~d}$ \\
\hline Spruce & 0 & 0 & 0 & 0 \\
\hline Mongolian pine & 0 & 0 & 0 & 1 \\
\hline Castor fiber & 0 & 3 & 4 & 4 \\
\hline Camphor & 0 & 0 & 0 & 1 \\
\hline Toon & 0 & 0 & 1 & 1 \\
\hline Teak & 0 & 0 & 1 & 1 \\
\hline Sweetgum & 0 & 1 & 2 & 2 \\
\hline E. urophylla & 0 & 1 & 1 & 2 \\
\hline E. grandis $\times$ E. urophylla & 0 & 1 & 1 & 2 \\
\hline
\end{tabular}



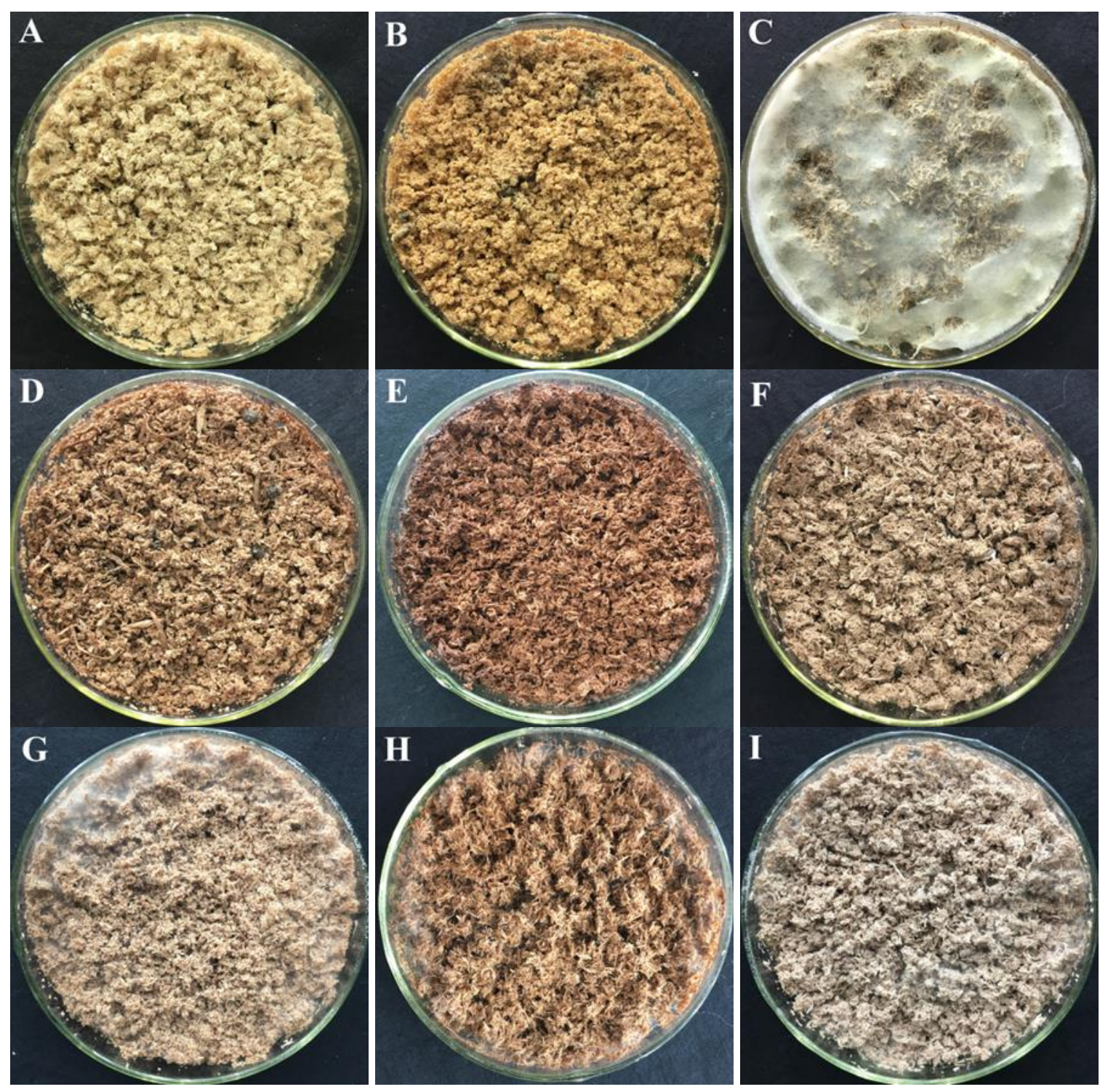

Fig. 1. Mold resistances of various wood flour species after 28 days exposure to molds: $(A)$ spruce; (B) Mongolian pine; (C) castor fiber; (D) camphor; (E) toon; (F) teak; (G) sweetgum; (H) E. urophylla; (I) E. grandis $\times$ E. urophylla

\section{SEM Examination of Wood Flour before and after Mold Resistance Test}

SEM images of various wood flour species before and after mold resistance tests are shown in Fig. 2, which directly reveal the extent of mold growth, distribution, spores, and hyphae on the wood flour samples. The wood flour before mold fungi tests were used as the control samples (Figs. 2A1-I1). As shown in Figs. 2AI-I1, no mold spores and hyphae were found on surfaces for all the control wood flour. However, big differences can be observed among the nine wood flours after 28 days treatment with molds. For spruce wood flour, there was no hyphae, and spores were found on its surface (Fig. 2A2), which corresponded the mold rating of 0 . Furthermore, the surfaces of the Mongolian pine and camphor wood flour samples (Figs. 2B2 and D2) were covered with only a few spores. 
A greater number of hyphae and spores were observed in the toon and teak wood flours (Figs. 2E2 and F2). These observations were consistent with the mold ratings mentioned above. Figures 2G2, H2, and I2 show a high degree of colonization and mold growth on the surfaces of sweetgum and two species of eucalyptus wood flours $(E$. urophylla and E. grandis $\times E$. urophylla), in which the spores were occasionally produced either individually or in short chains.

In castor fiber, the mold formed a dense hyphal network and produced large fruiting structures that released large numbers of spores on the outside of castor fibers, as shown in Fig. 2c. This mold colonization strategy releases of enzymes and organic acids into the interior regions of the wood. The surface elemental composition was affected and showed different degrees of hyphal penetrations (De Boer et al. 2010; Mansour and Salem 2015; Mansour et al. 2015).
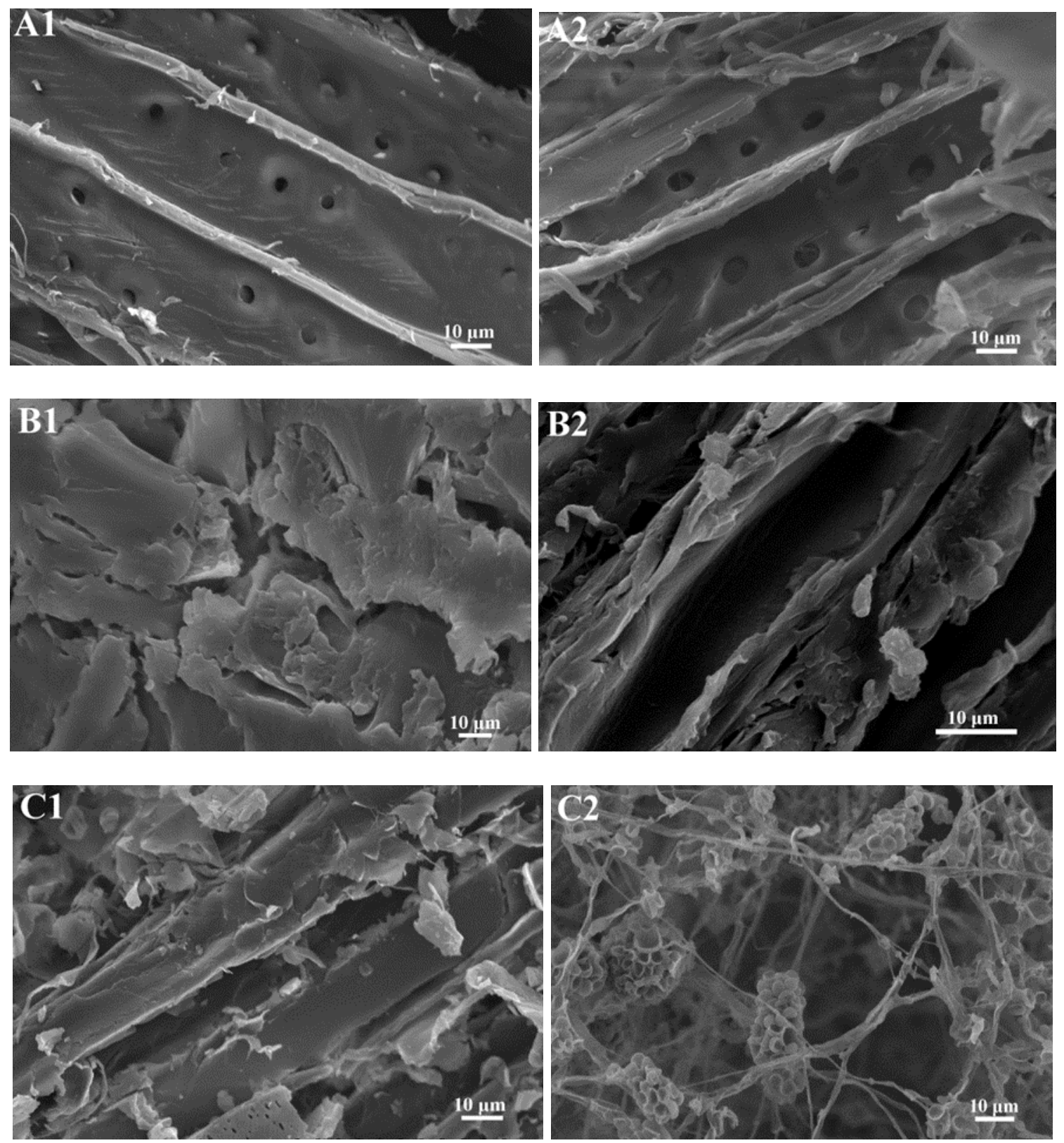


\section{bioresources.com}
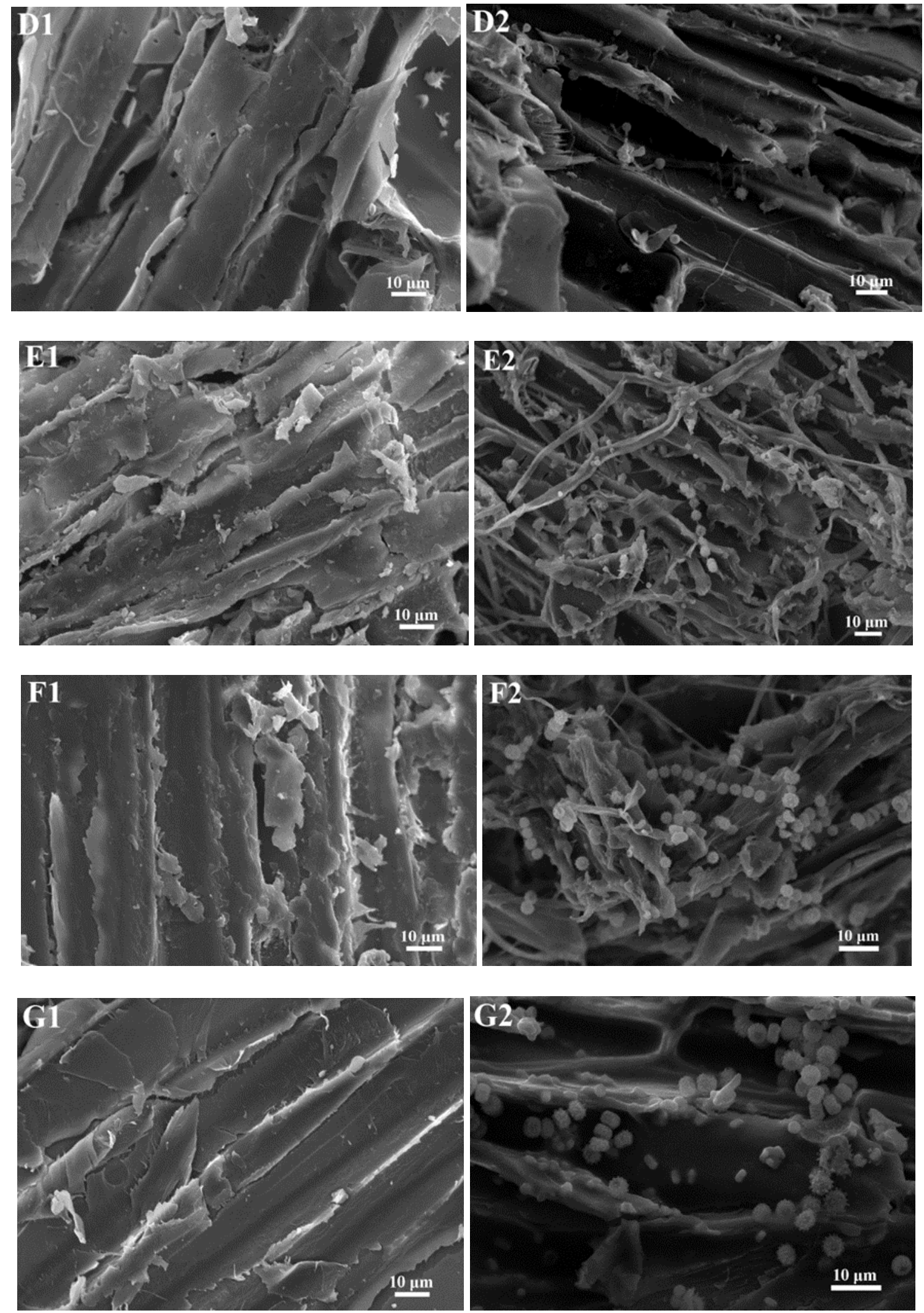

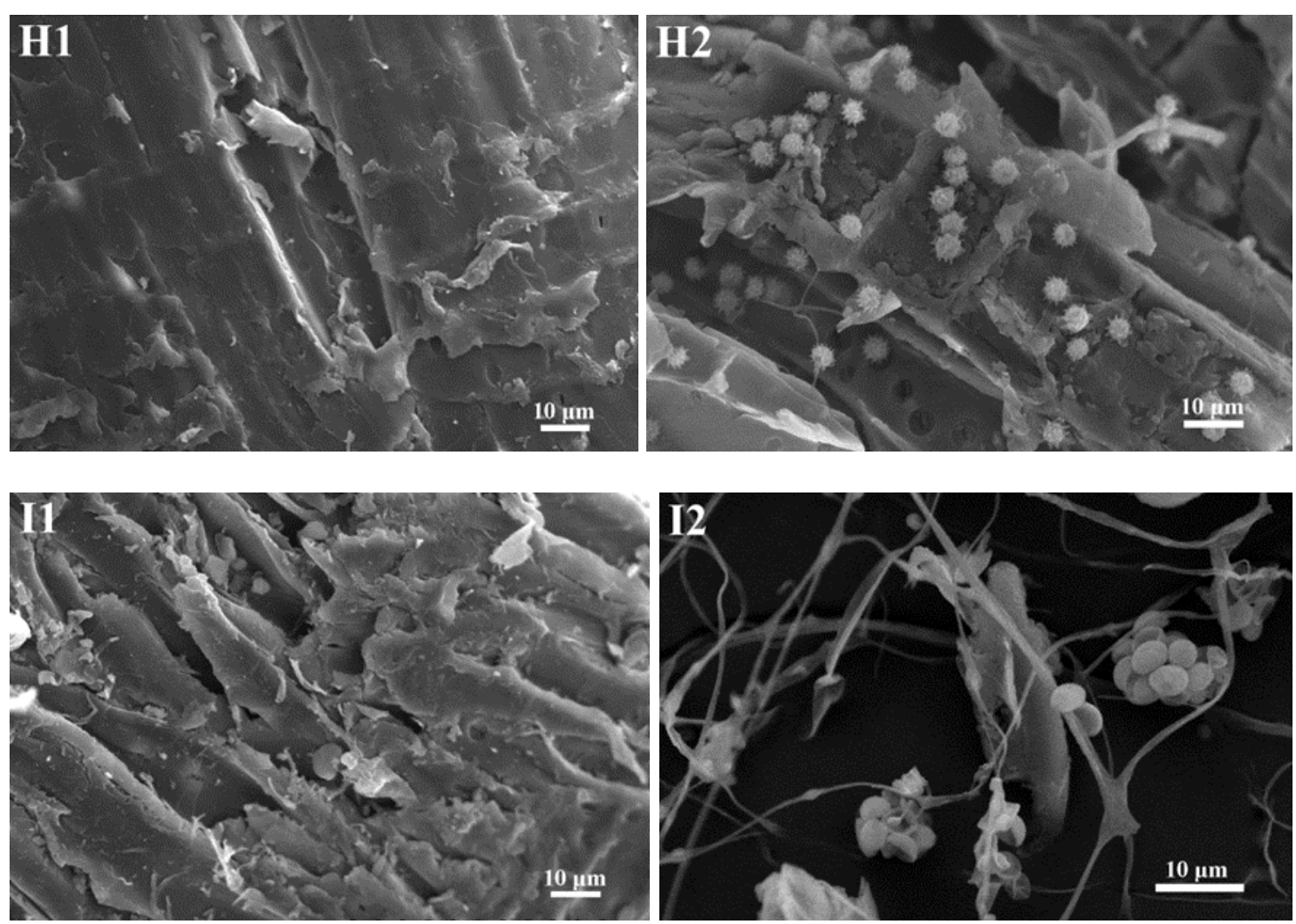

Fig. 2. SEM images of various wood flour species before (A1-I1) and after (B2-I2) mold resistance tests: (A) spruce; (B) Mongolian pine; (C) castor fiber; (D) camphor; (E) toon; (F) teak; (G) sweetgum; (H) E. urophylla; (I) E. grandis $\times$ E. urophylla

\section{Chemical Components of Various Wood Flour Species}

To investigate the differences in mold resistance between the nine wood flour species, extractives of each wood flour sample were analyzed by GC-MS. The chemical compounds and their relative contents are listed in Tables 3 through 11.

Seventeen compounds were identified in spruce wood flour extractives (Table 3). The major components included $\beta$-sitosterol (33.7\%), $\gamma$-sitosterol (24.32\%), and cedrol $(15.23 \%)$. These compounds display strong antifungal activities against a wide variety of fungi, such as Fusarium moniliforme, A. niger, Cladosporium cladosporioides, Phytophthora infestans, Penicillium notatum, Lenzites betulina, Trametes versicolor, Laetiporus sulphureus, Gloeophyllum trabeum, Rhizoctonia solani, F. solani, Pestalotiopsis funereal, and Ganoderma australe (Lall et al. 2006; Cheng et al. 2011; Zhang et al. 2011; Cheng et al. 2012; Choi et al. 2017). Vanillin (2.36\%), $\alpha$-cedrene (2.63\%), and $\beta$-cedrene $(2.73 \%)$ were also likely responsible for the resistance to the mold attack. Vanillin has inhibitory properties against fungi and bacteria and has a synergistic effect to enhance the antifungal effect of plant essential oils against Botrytis cinerea (Rattanapitigorna et al. 2006; Cava-Roda et al. 2012). Cedrene ( $\alpha$-Cedrene and $\beta$-Cedrene) is a major constituent of essential oils; it displays inhibitory effects against leukemia, anaerobic bacteria, yeast, and some decay fungi (Nibret and Wink 2010; Mun and Prewitt 2011). Because spruce wood contains more than $80 \%$ content of compounds with notable antifungal activities, it has an outstanding resistance to mold growth and decay. 
Table 3. Chemical Compounds and Their Relative Contents in Spruce Wood Flour

\begin{tabular}{|c|c|c|}
\hline Wood Species & Chemical Component & Relative Content (\%) \\
\hline Spruce & Vanillin & 2.36 \\
\hline & $\alpha$-Cedrene & 2.63 \\
\hline & $\beta$-Cedrene & 2.73 \\
\hline & Cedrol & 15.23 \\
\hline & Heptadecane & 2.27 \\
\hline & Octadecane & 2.51 \\
\hline & Labda-8(20),12,14-triene & 1.31 \\
\hline & $27-$-Nor-25-ketocholesterol & 5.16 \\
\hline & Tetracosane & 3.84 \\
\hline & $\beta$-Sitosterol & 33.70 \\
\hline & Triacontane & 3.94 \\
\hline & $\gamma$-Sitosterol & 24.32 \\
\hline
\end{tabular}

Table 4. Chemical Compounds and Their Relative Contents in Mongolian Pine Wood Flour

\begin{tabular}{|c|c|c|}
\hline Wood Species & Chemical Component & Relative Content (\%) \\
\hline Mongolian pine & Benzyl alcohol & 3.06 \\
\hline & Benzothiazole & 3.09 \\
\hline & Vanillin & 45.89 \\
\hline & 3'-Hydroxy-4'-methoxyacetophenone & 18.57 \\
\hline & Heptadecane & 10.91 \\
\hline & 4-Hydroxy-3-methoxycinnamaldehyde & 8.84 \\
\hline & Octadecane & 5.16 \\
\hline & Nonacosane & 1.41 \\
\hline & 1-lodo-octadecane & 3.07 \\
\hline
\end{tabular}

Nine compounds were identified in Mongolian pine extractives (Table 4). Among these compounds, vanillin (45.89\%) is the most abundant compound, which is used in medical applications and as a flavoring agent because of its strong activity against bacteria, yeasts, and fungi (Rattanapitigorna et al. 2006; Cava-Roda et al. 2012). Benzyl alcohol (3.06\%), benzothiazole (3.09\%), and 4-hydroxy-3-methoxycinnamaldehyde $(8.84 \%)$ also play an important role in fungal durability of the Mongolian pine. Benzyl alcohol exhibits significant antifungal activities towards Colletorichum camelliae (Zhang et al. 2006). Benzothiazole and its derivatives are important fragments in medicinal chemistry due to their wide range of biological activities, which include anti-tumor, anti-cancer, antiinflammatory, anti-viral, and anti-fungal activities against Alternaria solani and Botrytis cinerea (Seenaiah et al. 2014; Gao et al. 2017). 4-Hydroxy-3-methoxycinnamaldehyde has been described as an antifungal compound due to its ability to inhibit the growth of Fusarium verticillioides (Carpinella et al. 2003). These compounds synergistically improved the fungal resistance of Mongolian pine wood.

The GC-MS of castor fiber showed twenty compounds (Table 5). The main components were palmitic acid (17.57\%), octadec-9-enoic acid (14.08\%), 4-ethenyl-1,4dimethyl-3-(2-methylprop-1-enyl), and cycloheptene (10.82\%). The chemical components responsible for mold resistance were palmitic acid and $\gamma$-sitosterol. The former is a fatty acid that is widely distributed in the extractives of plants and displays a strong inhibiting 
effect on the growth of Alternaria solani, Colletotrichum lagenarium, and Fusarium oxysporum (Liu et al. 2008). The latter is an epimer of $\beta$-sitosterol. Both $\beta$-sitosterol and $\gamma$-sitosterol show strong antimicrobial activities against some bacteria and fungi. Although palmitic acid and $\gamma$-sitosterol provided some antifungal activity for castor fiber, these compounds provided poorer fungal resistance than in the other wood flour because of their lower relative content $(17.57 \%$ and $2.06 \%$, respectively).

Table 5. Chemical Compounds and Their Relative Contents in Castor Fiber Flour

\begin{tabular}{|c|c|c|}
\hline Wood Species & Chemical Component & Relative Content (\%) \\
\hline \multirow[t]{17}{*}{ Castor fiber } & 5-Hydroxy-2-decenoic acid lactone & 7.89 \\
\hline & 2-Methoxy-4-vinylphenol & 3.78 \\
\hline & 3-Hydroxy-4-methoxybenzoic acid & 4.06 \\
\hline & 3-Ethoxybenzaldehyde & 3.36 \\
\hline & D-arabinitol & 3.39 \\
\hline & Palmitic acid & 17.57 \\
\hline & Ricinine & 5.24 \\
\hline & Octadec-9-enoic acid & 14.08 \\
\hline & Octadecanoic acid & 4.86 \\
\hline & $\begin{array}{c}\text { 1-Cyclopropene-1-pentanol, } \alpha, \varepsilon, \varepsilon, 2 \text {-tetramethyl- } \\
\text { 3-(1-methylethenyl)- }\end{array}$ & 3.91 \\
\hline & $\begin{array}{l}\text { 4-Ethenyl-1,4-dimethyl-3-(2-methylprop-1-enyl) } \\
\text { cycloheptene }\end{array}$ & 10.82 \\
\hline & $\begin{array}{c}\text { (1R)-7 } \beta \text {-Ethenyl-1,2,3,4,4a, } 4 \mathrm{~b} \alpha, 5,6,7,9,10,10 \mathrm{a} \alpha- \\
\text { dodecahydro- } 2 \beta \text {-hydroxy-1,4a } \beta, 7 \text {-trimethyl- } 1 \alpha \text { - } \\
\text { phenanthrenemethanol }\end{array}$ & 3.77 \\
\hline & 12-Ethylsophoramine & 7.53 \\
\hline & $\begin{array}{l}\text { 9-Methoxy-4-(2-methylbut-3-en-2yl)furo[3,2- } \\
\text { g]chromen-7-one }\end{array}$ & 2.89 \\
\hline & $\begin{array}{c}y \text {-Sitosterol } \\
\end{array}$ & 2.06 \\
\hline & 4,22-Stigmastadiene-3-one & 1.50 \\
\hline & $\beta$-Sitostenone & 3.29 \\
\hline
\end{tabular}

In camphor wood extractives, the main compounds were 1-docosene (14.47\%) and $\gamma$-sitosterol (33.87\%). The following seven compounds, elemol (4.61\%), cedrol $(3.73 \%)$, palmitic acid (8.84\%), elaidic acid (1.51\%), campesterol (5.60\%), stigmasterol $(2.52 \%)$, and $\gamma$-sitosterol, were the key components that imparted camphor wood flour with fungal resistance (Table 6).

The antifungal activities of cedrol, palmitic acid, and $\gamma$-sitosterol have been described above. Elemol, extracted from the fresh rhizomes of Zingiber officinale, was reported to show a fungistatic activity against Penicillium griseofulvum (Philippe et al. 2012). Elaidic acid is an unsaturated fatty acid, which shows strong antiradical, antibacterial, anticandidal, and antifungal activities against $A$. niger and $A$. flavus (Hanene et al. 2015). Campesterol and stigmasterol are the most important plant sterols that are often present in lipid-rich plant foods such as olive oil, nuts, legumes, and seeds. The antifungal activities of campesterol and stigmasterol against Phytophthora infestans have been reported by Choi et al. (2017). 
Table 6. Chemical Compounds and Their Relative Contents in Camphor Wood Flour

\begin{tabular}{|c|c|c|}
\hline Wood Species & Chemical Component & Relative Content (\%) \\
\hline Camphor & $\begin{array}{c}\text { 3-Ethyl-5-(3-ethyl-2(3H)-benzothiazolylidene)-2- } \\
\text { (p-tolylimino)-4-thiazolidinone }\end{array}$ & 1.80 \\
\hline & Bornane-2,5-dione & 4.43 \\
\hline & Elemol & 4.61 \\
\hline & Cedrol & 3.73 \\
\hline & $\begin{array}{c}\text { 1,4-Methanoazulen-9-one,decahydro-1,5,5,8a- } \\
\text { tetramethyl-, [1R-(1a,3aß,4a,8aß)]- }\end{array}$ & 7.69 \\
\hline & Palmitic acid & 8.84 \\
\hline & Elaidic acid & 1.51 \\
\hline & Octadecanoic acid & 2.40 \\
\hline & 9-Octadecenamide, (Z)- & 1.48 \\
\hline & 3-Eicosene,(E)- & 2.20 \\
\hline & 1-Docosene & 14.47 \\
\hline & Campesterol & 5.60 \\
\hline & Stigmasterol & 2.52 \\
\hline & $\gamma$-Sitosterol & 33.87 \\
\hline & $\beta-$ Sitostenone & 4.08 \\
\hline
\end{tabular}

There were in total six compounds that affected the fungal resistance of toon wood, namely $\gamma$-sitosterol (23.37\%), cycloeucalenol (16.97\%), palmitic acid (12.14\%), 3,4dihydroxybenzoic acid (3.56\%), vanillin (2.15\%), and $\alpha$-muurolene (2.10\%) (Table 7). As mentioned above, $\gamma$-sitosterol, palmitic acid, and vanillin possess strong antifungal properties. Both cycloeucalenol and 3,4-dihydroxybenzoic acid exhibited antifungal activity against $A$. niger, Candida albicans, and Cryptococcus neoformans (Ocharo 2012; Amugune 2013). $\alpha$-Muurolene displays antifungal activity against the phytopathogenic fungus Cladosporium cucumerinum (Ali et al. 2008).

Table 7. Chemical Compounds and Their Relative Contents in Toon Wood Flour

\begin{tabular}{|c|c|c|}
\hline Wood Species & Chemical Component & Relative Content (\%) \\
\hline Toon & Catechol & 7.51 \\
\hline & Vanillin & 2.15 \\
\hline & $\alpha$-Muurolene & 2.10 \\
\hline & d-Cadinene & 3.40 \\
\hline & 3-Hydroxy-4-methoxybenzoic acid & 5.81 \\
\hline & 1,6-Dimethyl-4-propan-2-ylnaphthalene & 8.49 \\
\hline & 3,4-Dihydroxybenzoic acid & 3.56 \\
\hline & Methyl palmitate & 3.85 \\
\hline & Palmitic acid & 12.14 \\
\hline & Octadecanoic acid & 2.55 \\
\hline & 9-Octadecenamide, (Z)- & 2.08 \\
\hline & c-Methoxy-4',5'-methylenedioxybiphenyl-2- & 6.03 \\
\hline & carboxylic acid & 23.37 \\
\hline & Y-Sitosterol & 16.97 \\
\hline
\end{tabular}


Fifteen compounds were found in the sweetgum wood extractive (Table 8). There were two main components consisting of syringic acid (19.87\%) and 5-hydroxymethylfurfural (15.19\%). Syringic acid is an active phenolic compound, which has been reported to possess anti-diabetic, antibacterial, and antifungal properties towards Botrytis cinerea and Ganoderma boninense (Chong et al. 2012; Mendoza et al. 2016). 5-Hydroxymethylfurfural is an organic compound with a special fragrance, which serves as a nutritional source for fungi. It promotes and interferes with the growth of microorganisms, which has a negative effect on the fungal durability of sweetgum wood (Rosatella et al. 2011; Van Putten et al. 2013). In addition, six compounds, including vanillin (5.84\%), syringaldehyde (8.69\%), 4-hydroxy-3-methoxycinnamaldehyde (5.82\%), palmitic acid (8.57\%), 3,5dimethoxy-4-hydroxycinnamaldehyde (2.78\%), and $\gamma$-sitosterol $(6.55 \%)$, were likely responsible for the resistance of the sweetgum wood against mold attack. Of these compounds, vanillin, palmitic acid, 4-hydroxy-3-methoxycinnamaldehyde, and $\gamma$-sitosterol were also present in other wood flour extractives and showed antifungal properties. Syringaldehyde is a phenolic compound, which exhibited antifungal activity against Leucoagaricus gongylophorus (De Souza et al. 2005). The 3,5-dimethoxy-4-hydroxycinnamaldehyde significantly affected the fungal growth and metabolism, which suggests that this molecule can be developed as an antifungal agent (Shreaz et al. 2013). Overall, the final mold resistance of sweetgum wood could be attributed to the synergistic action arising from the positive and negative effects provided by these antifungal components and 5-hydroxymethylfurfural, respectively.

Table 8. Chemical Compounds and Their Relative Contents in Sweetgum Wood Flour

\begin{tabular}{|c|c|c|}
\hline Wood Species & Chemical Component & Relative Content (\%) \\
\hline Sweetgum & Catechol & 1.62 \\
\hline & 5-Hydroxymethylfurfural & 15.19 \\
\hline & Vanillin & 5.84 \\
\hline & 3-Hydroxy-4-methoxybenzoic acid & 7.25 \\
\hline & 3,4,5-Trimethoxyphenol & 2.69 \\
\hline & Syringaldehyde & 8.69 \\
\hline & S-Hydroxy-3-methoxycinnamaldehyde & 5.82 \\
\hline & Syringic acid & 19.78 \\
\hline & Palmitic acid & 8.57 \\
\hline & Or-Dimethoxy-4-hydroxycinnamaldehyde & 2.78 \\
\hline & Octadecanoic acid & 7.21 \\
\hline & Cinnamic acid cinnamyl ester & 4.26 \\
\hline & 1-Docosanol & 2.37 \\
\hline & r-Sitosterol & 6.55 \\
\hline & Stigmastanol & 1.37 \\
\hline
\end{tabular}

Twelve chemical components were found in the teak wood extractives (Table 9). Four main components with relatively high contents were 2-methylanthraquinone (22.50\%), 2-hydroxymethylanthraquinone (18.36\%), palmitic acid (10.75\%), and squalene $(10.74 \%)$. The compounds responsible for mold resistance were 2-hydroxymethylanthraquinone, vanillin (8.65\%), palmitic acid, $\gamma$-sitosterol $(8.75 \%)$, and cycloeucalenol $(8.98 \%)$. Of these, 2-hydroxymethylanthraquinone possess some antifungal properties and plays an important role against the production of A. niger (Sumthong 2007). 
Table 9. Chemical Compounds and Their Relative Contents in Teak Wood Flour

\begin{tabular}{|c|c|c|}
\hline Wood Species & Chemical Component & Relative Content (\%) \\
\hline Teak & Vanillin & 8.65 \\
\hline & 4-((1E)-3-Hydroxy-1-propenyl)-2-methoxyphenol & 1.48 \\
\hline & Palmitic acid & 10.75 \\
\hline & N-(2-nitrosoacenaphthylen-1-yl)hydroxylamine & 1.69 \\
\hline & 2-Methylanthraquinone & 22.50 \\
\hline & Methyl 10-trans,12-cis-octadecadienoate & 3.09 \\
\hline & 2-Hydroxymethylanthraquinone & 18.36 \\
\hline & Squalene & 10.74 \\
\hline & (E,E,E)-geranylgeraniol & 1.55 \\
\hline & Stigmasterol & 3.45 \\
\hline & $\gamma$-Sitosterol & 8.75 \\
\hline & Cycloeucalenol & 8.98 \\
\hline
\end{tabular}

Thirteen compounds were identified in the wood extractives of $E$. grandis $\times E$. urophylla, the main ones being palmitic acid $(28.01 \%)$ and $\gamma$-sitosterol (17.62\%) (Table $10)$. Both inhibited the mycelial growth of mold and decay fungi. In addition, vanillin $(4.68 \%)$, syringaldehyde $(4.80 \%)$, and syringic acid $(2.11 \%)$ were also instrumental in the improvement of the resistance against fungal attack.

Table 10. Chemical Compounds and Their Relative Contents in E. grandis $\times E$. urophylla Wood Flour

\begin{tabular}{|c|c|c|}
\hline Wood Species & Chemical Component & Relative Content (\%) \\
\hline $\begin{array}{c}\text { E. grandis } \times \text { E. } \\
\text { urophylla }\end{array}$ & Vanillin & 4.68 \\
\hline & 3-Hydroxy-4-methoxybenzoic acid & 5.32 \\
\hline & Syringaldehyde & 4.80 \\
\hline & Heptadecane & 2.53 \\
\hline & 4-((1E)-3-Hydroxy-1-propenyl)-2-methoxyphenol & 3.82 \\
\hline & Syringic acid & 2.11 \\
\hline & Palmitic acid & 28.01 \\
\hline & Heptadecanoic acid & 7.19 \\
\hline & Octadecanoic acid & 5.85 \\
\hline & 1-Heptacosanol & 2.78 \\
\hline & 4-Methoxy-4',5'-methylenedioxybiphenyl-2- & 8.84 \\
\hline & carboxylic acid & 17.62 \\
\hline & Y-Sitosterol & 6.44 \\
\hline
\end{tabular}

As for E. urophylla wood extractives, syringaldehyde (22.76\%), vanillin (13.70\%), 4-hydroxy-3-methoxycinnamaldehyde (12.28\%), syringic acid (4.35\%), benzyl alcohol $(2.06 \%)$, and $\gamma$-sitosterol $(1.42 \%)$ were the key compounds responsible for fungal resistance (Table 11). These six compounds were also present in the other wood flour extractives, and the antifungal activities were described above. As a result, the final resistance of E. urophylla wood to the molds is the comprehensive effect of these compounds. 
Table 11. Chemical Compounds and Relative Contents in E. urophylla Wood Flour

\begin{tabular}{|c|c|c|}
\hline Wood Species & Chemical Component & Relative Content (\%) \\
\hline E. urophylla & Benzyl alcohol & 2.06 \\
\hline & Benzaldehyde dimethyl acetal & 3.24 \\
\hline & 2,6-Dimethoxyphenol & 1.64 \\
\hline & Vanillin & 13.70 \\
\hline & Apocynin & 2.54 \\
\hline & 3-Hydroxy-4-methoxybenzoic acid & 22.16 \\
\hline & Syringaldehyde & 22.76 \\
\hline & 4-Hydroxy-3-methoxycinnamaldehyde & 12.28 \\
\hline & Syringic acid & 4.35 \\
\hline & 3,5-Dimethoxy-4-hydroxycinnamaldehyde & 9.51 \\
\hline & Octadecanoic acid & 2.62 \\
\hline & E-15-Heptadecenal & 1.70 \\
\hline & V-Sitosterol & 1.42 \\
\hline
\end{tabular}

The total contents of antifungal compounds in all the wood flour extractives were $80.97 \%$ in spruce wood, $60.88 \%$ in Mongolian pine, $19.63 \%$ in castor fiber, $60.68 \%$ in camphor wood, $60.29 \%$ in toon wood, $42.84 \%$ in sweetgum wood, $55.49 \%$ in teak wood, $57.74 \%$ in E. grandis $\times$ E. urophylla wood, and $56.57 \%$ in E. urophylla wood. This result was consistent with the sequence of resistance towards molds of different wood flours. This suggested that the natural durability of wood flour against fungi could be affected by their chemical components that could provide potentially positive or negative effects on the susceptibility or resistance to fungi.

\section{CONCLUSIONS}

1. Visual and SEM observations revealed that there were large differences in mold resistances between the nine wood flour species. The sequence of mold resistance of different wood flours is as follows: spruce $>$ Mongolian pine and camphor $>$ toon and teak $>$ eucalyptus $($ E. urophylla and E. grandis $\times$ E. urophylla) $>$ sweetgum $>$ castor straw fiber.

2. The GC-MS analysis illustrated that the total content of the antifungal compounds present in all wood flour extractives were $80.97 \%$ in spruce, $60.88 \%$ in Mongolian pine, $19.63 \%$ in castor fiber, $60.68 \%$ in camphor, $60.29 \%$ in toon, $42.84 \%$ in sweetgum, $55.49 \%$ in teak, $57.74 \%$ in E. grandis $\times$ E. urophylla, and $56.57 \%$ in E. urophylla. This was well consistent with the sequence of mold resistance of different wood flour samples and suggested that the natural durability of wood flour against fungi could be significantly affected by their chemical composition.

\section{ACKNOWLEDGMENTS}

The authors are grateful for the support of the Science and Technology Planning Project of Guangdong Province, China (Grant No. 2015 A010105019 and 2015A030302056) and the Science and Technology Planning Project of Guangzhou City, China (Grant No. 201604016096). 


\section{REFERENCES CITED}

Ali, N. A. A., Wurster, M., Arnold, N., Lindequis, U., and Wessjohan, L. (2008). "Essential oil composition from oleogum resin of soqotraen Commiphora kua," Records of Natural Products 2(3), 70-75.

Amugune, B. K. M. (2013). "Screening of Ten Selected Medicinal Plants for Antibacterial and Anti-fungal Activity and the Isolation and Characterization of Bioactive Constituents from Alectra sessiliflora (vahl) kuntze and Blumea axillaris (Lam.) dc, $\mathrm{Ph}$. D. Dissertation, University of Nairobi, Nairobi, Kenya.

ASTM G21 (2013). "Standard practice for determining resistance of synthetic polymeric materials to fungi," ASTM International, West Conshohocken, PA.

Carpinella, M. C., Giorda, L. M., Ferrayoli, C. G., and Palacios, S. M. (2003). "Antifungal effects of different organic extracts from Melia azedarach L. on phytopathogenic fungi and their isolated active components," Journal of Agricultural and Food Chemistry 51(9), 2506-2511. DOI: 10.1021/jf026083f

Cava-Roda, R. M., Taboada-Rodríguez, A., Valverde-Franco, M. T., and Marín-Iniesta, F. (2012). "Antimicrobial activity of vanillin and mixtures with cinnamon and clove essential oils in controlling Listeria monocytogenes and Escherichia coli O157:H7 in milk," Food and Bioprocess Technology 5(6), 2120-2131. DOI: 10.1007/s11947-0100484-4

Cheng, S. S., Lin, C. Y., Gu, H. J., and Chang, S. T. (2011). "Antifungal activities and chemical composition of wood and leaf essential oils from Cunninghamia konishii," Journal of Wood Chemistry and Technology 31(3), 204-217. DOI: 10.1080/02773813.2010.515049

Cheng, S. S., Chung, M. J., Lin, C. Y., Wang, Y. N., Chang, S. T. (2012).

"Phytochemicals from Cunninghamia konishii Hayataact as antifungal agents," Journal of Agricultural and Food Chemistry 60(1), 124-128. DOI: 10.1021/jf2042196

Choi, N. H., Jang, J. Y., Choi, G. J., Choi, Y. H., Jang, K. S., Nguyen, V. T., Min, B. S., Dang, Q. L., and Kim, J. C. (2017). "Antifungal activity of sterols and dipsacus saponins isolated from Dipsacus asper roots against phytopathogenic fungi," Pesticide Biochemistry and Physiology 141, 103-108. DOI: 10.1016/j.pestbp.2016.12.006

Chong, K. P., Atong, M., and Rossall, S. (2012). "The role of syringic acid in the interaction between oil palm and Ganoderma boninense, the causal agent of basal stem rot," Plant Pathology 61(5), 953-963. DOI: 10.1111/j.1365-3059.2011.02577

DeBoer, W., Folman, L. B., Gunnewiek, P. J., Svensson, T., Bastviken, D., Öberg, G., DelRio, J. C., and Boddy, L. (2010). "Mechanism of antibacterial activity of the white-rot fungus Hypholoma fasciculare colonizing wood," Canadian Journal of Microbiology 56(5), 380-388. DOI: 10.1139/w10-023

De Souza, R. C., Fernandes, J. B., Vieira, P. C., Silva, M. Fátima, G. F, Godoy, M. F. P., Pagnocca, F. C., Bueno, O. C., Hebling, M. J. A., and Piranic, J. R. (2005). “A new imidazole alkaloid and other constituents from Pilocarpus grandiflorus and their antifungal activity," Zeitschrift für Naturforschung B 60(7), 787-791.

DOI: $10.1515 / \mathrm{znb}-2005-0715$

Durmaza, S., Özgenç, Ö., Boyacı, İ. H., Yıldız, Ü. C., and Erişir, E. (2016). "Examination of the chemical changes in spruce wood degraded by brown-rot fungi using FT-IR and FT-Raman spectroscopy," Vibrational Spectroscopy 85, 202-207.

DOI: 10.1016/j.vibspec.2016.04.020 
Fojutowski, A., Koziróg, A., Kropacz, A., and Noskowiak, A. (2014). "The susceptibility of some acetylated hardwood species to mould fungi attack-An attempt to objectify the assessment," International Biodeterioration and Biodegradation 86(1), 60-65. DOI: 10.1016/j.ibiod.2013.08.007

Gao, Z. F., Zhang, B. J., Liu, H. P., Han, J. C., and Zhang, Y. J. (2017). "Identification of endophytic Bacillus velezensis ZSY-1 strain and antifungal activity of its volatile compounds against Alternaria solani and Botrytis cinerea," Biological Control 105, 27-39. DOI: 10.1016/j.biocontrol.2016.11.007

Hanene, G., Aouadhi, C., Hamrouni, S., and Mnif, W. (2015). "Antibacterial, antifungal, and antioxidant activities of tunisian Oleaeuropaea ssp. oleaster fruit pulp and its essential fatty acids," International Journal of Pharmacy and Pharmaceutical Sciences 7(1), 52-55.

Jeloková, E., and Šindler, J. (2001). "Testing of some chemical compounds for wood protection," Drevo 56, 137-138.

Kartal, S. N., Aysal, S., Terzi, E., Yılgör, N., Yoshimura, T., and Tsunoda, K. (2013). "Wood and bamboo-PP composites- Fungal and termite resistance, water absorption, and FT-IR analyses," BioResources 8(1), 1222-1244. DOI: 10.15376/biores.8.1.12221244

Lall, N., Weiganand, O., Hussein, A. A., and Meyer, J. J. M. (2006). "Antifungal activity of naphthoquinones and triterpenes isolated from the root bark of Euclea natalensis," South African Journal of Botany 72(4), 579-583. DOI: 10.1016/j.sajb.2006.03.005

Li, M.Y., Cheng, S. C., Li, D., Wang, S. N., Huang A. M., and Sun, S. Q. (2015). "Structural characterization of steam-heat treated Tectona grandis wood analyzed by FT-IR and 2D-IR correlation spectroscopy," Chinese Chemical Letters 26(2), 221225. DOI: 10.1016/j.cclet.2014.11.024

Liu, S. Y., Ruan, W. B., Li, J., Xu, H., Wang, J. G., Gao, Y. B., and Wang, J. G. (2008). "Biological control of phytopathogenic fungi by fatty acids," Mycopathologia 166(2), 93-102. DOI: 10.1007/s11046-008-9124-1

Mansour, M. M. A., and Salem, M. Z. M. (2015). "Evaluation of wood treated with some natural extracts and Paraloid B-72 against the fungus Trichoderma harzianum- Wood elemental composition, in-vitro, and application evidence," International Biodeterioration and Biodegradation 100(C), 62-69. DOI: 10.1016/j.ibiod.2015.02.009

Mansour, M. M. A., Abdel-Megeed, A., Nasser, R. A., and Salem, M. Z. M. (2015). "Comparative evaluation of some woody trees methanolic extractsand Paraloid B-72 against phytopathogenic mold fungi Alternaria tenuissima and Fusarium culmorum," BioResources 10(2), 2570-2584. DOI: 10.15376/biores.10.2.2570-2584

Mendoza, L., Castro, P., Melo, R., Campos, A. M., Zúñiga, G., Guerrero, J., and Cotoras, M. (2016). "Improvement of the antifungal activity against Botrytis cinerea of syringic acid, a phenolic acid from grape pomace," Journal of the Chilean Chemical Society 61(3), 3039-3042. DOI: 10.4067/S0717-97072016000300006

Mun, S. P., and Prewitt, L. (2011). "Antifungal activity of organic extracts from Juniperus virginiana heartwood against wood decay fungi," Forest Products Journal 61(6), 443-449. DOI: 10.13073/0015-7473-61.6.443

Nibret, E., and Wink, M. (2010). "Trypanocidal and antileukaemic effects of the essential oils of Hagenia abyssinica, Leonotis ocymifolia, Moringa stenopetala, and their main individual constituents," Phytomedicine 17(12), 911-920. DOI:

10.1016/j.phymed.2010.02.009 
Ocharo, C. M. (2012). Isolation and Identification of Antibacterial and Antifungal Compounds from Selected Kenyan Medicinal Plants, Master's Thesis, Kenyatta University, Nairobi, Kenya.

Sumthong P. (2007). Antimicrobial Compounds as Side Products from the Agricultural Processing Industry. Chapter 4 - Isolation and Elucidation of Quinones in Tectona grandis, Ph. D Dissertation, University of Leiden, Leiden, Netherlands.

Philippe, S., Souaïbou, F., Jean-Pierre, N., Brice, F., Paulin, A., Issaka, Y., and Dominique, S. (2012). "Chemical composition and in vitro antifungal activity of zingiber officinale essential oil against foodborne pathogens isolated from a traditional cheese wagashi produced in Benin," International Journal of Biosciences 2(9), 20-28.

Rattanapitigorna, P., Arakawa, M., and Tsuro, M. (2006). "Vanillin enhances the antifungal effect of plant essential oils against Botrytis cinerea," International Journal of Clinical Aromatherapy 16(3-4), 193-198. DOI: 10.1016/j.ijat.2006.09.003

Rosatella, A. A., Simeonov, S. P., Frade, R. F. M., and Afonso, C. A. M. (2011). "ChemInform abstract- Hydroxymethylfurfural (HMF) as a building block platform: biological properties, synthesis, and synthetic applications," Green Chemistry 13(4), 754-793. DOI: 10.1002/chin.201132258

Salem, M. Z. M. (2016). "EDX measurements and SEM examination of surface of some imported woods inoculated by three mold fungi," Measurement 86, 301-309. DOI: 10.1016/j.measurement.2016.03.008

Salem, M. Z. M., Mansour, M. M. A., Mohamed, W. S., Ali, H. M., and Hatamleh, A. A. (2017). "Evaluation of the antifungal activity of treated acacia saligna wood with paraloid B-72/ $\mathrm{TiO}_{2}$ nanocomposites against the growth of Alternaria tenuissima, Trichoderma harzianum, and Fusarium culmorum," BioResources 12(4), 7615-7627. DOI: 10.15376/biores. 12. 4.7615-7627

Seenaiah, D., Reddy, P. R., Reddy, G. M., Padmaja, A., Padmavathi, V., and Krishna, N. S. (2014). "Synthesis, antimicrobial, and cytotoxic activities of pyrimidinyl benzoxazole, benzothiazole, and benzimidazole," European Journal of Medicinal Chemistry 77(2), 1-7. DOI: 10.1016/j.ejmech.2014.02.050

Shreaz, S., Bhatia, R., Khan, N., Muralidhar, S., Manzoor, N., and Khan, L. A. (2013). "Influences of cinnamic aldehydes on $\mathrm{H}^{+}$extrusion activity and ultrastructure of candida," Journal of Medical Microbiology 62 (Pt 2), 232-240. DOI 10.1099/jmm.0.036145-0

Sirmah, P., Dumarçay, S., Masson, E., and Gérardin, P. (2009). "Unusual amount of (-)mesquitol from the heartwood of Prosopis juliflora," Natural Product Reserach 23(2), 183-189. DOI: 10.1080/14786410801940968

Sohail, M., Ahmad, A., and Khan, S. A. (2011). "Production of cellulases from Alternaria sp. MS28 and their partial characterization," Pakistan Journal of Botany 43 (6), 3001-3006.

Sterflinger, K., and Piñar, G. (2013). "Microbial deterioration of cultural heritage and works of art-tilting at windmills?" Applied Microbiology and Biotechnology 97(22), 9637-9646. DOI: 10.1007/s00253-013-5283-1

Van Putten, R. J., Van Der Waal, J. C., De Jong, E., Rasrendra, C.B., Heeres, H. J., and De Vries, J. G. (2013). "Hydroxymethylfurfural, a versatile platform chemical made from renewable resources," Chemical Reviews 113(3), 1499-1597. DOI:

$10.1021 / \mathrm{cr} 300182 \mathrm{k}$ 
Xu, K. M., Feng, J., Zhong, T. H., Zheng, Z. F., and Chen, T. A. (2015). "Effects of volatile chemical components of wood species on mould growth susceptibility and termite attack resistance of wood plastic composites," International Biodeterioration and Biodegradation 100, 106-115. DOI: 10.1016/j.ibiod.2015.02.002

Zhang, W. L., Abdel-Rahman, F. H., and Saleh, M. A. (2011). "Natural resistance of rose petals to microbial attack," Journal of Environmental Science and Health 46(5), 381393. DOI: $10.1080 / 03601234.2011 .572502$

Zhang, Z. Z., Li, Y. B., Qi, L., and Wan, X. C. (2006). “Antifungal activities of major tea leaf volatile constituents toward Colletorichum camelliae Massea," Journal of Agricultural and Food Chemistry 54(11), 3936-3940. DOI: 10.1021/jf060017

Article submitted: November 29, 2017; Peer review completed: February 25, 2018; Revised version received: April 7, 2018; Accepted: April 8, 2018; Published: July 11, 2018.

DOI: 10.15376/biores.13.3.6524-6541 